\title{
CLINICAL STUDY ON ACUTE SCROTAL SWELLINGS IN ADICHUNCHANAGIRI HOSPITAL AND RESEARCH CENTRE
}

Abinash Hazarika1, K. Santhosh Kumar², Partha Pratim Bora ${ }^{3}$

1 Professor, Department of General Surgery, Adichunchanagiri Institute of Medical Sciences.

2 Post Graduate, Department of General Surgery, Adichunchanagiri Institute of Medical Sciences.

${ }^{3}$ Post Graduate, Department of General Surgery, Adichunchanagiri Institute of Medical Sciences.

ABSTRACT
BACKGROUND AND OBJECTIVES
Acute scrotal swellings are the commonest swellings affecting both children and adults. Though these swellings are frequently
encountered, many a times correct diagnosis is not made and testes have been sacrificed. Therefore, the aim is to study the clinical
presentation, pathophysiology, differential diagnosis and management of acute scrotum with use of history, clinical examination and
investigations.

\section{METHODS}

The material for this study was obtained from patients admitted to general surgical wards of Adichunchanagiri Institute of Medical Sciences with acute scrotal swellings being included in the study from July 2013 to July 2015 and were evaluated clinically as well as with additional investigations.

\section{RESULTS}

Epididymo-orchitis was found to be the commonest (39 out of 90) followed by testicular torsion (19 cases) and Fournier's gangrene (15 cases). Acute scrotal swellings were common in younger individuals. The maximum incidence occurred during 3 rd decade. The average duration of pain from onset till presentation in case of epididymo-orchitis was 3.54 days and in case of Fournier's gangrene was 9.6 days. Haemogram, urine analysis were not conclusive but were supportive to clinical diagnosis. USG combined with Doppler has high accuracy in detecting testicular torsion. The period of hospitalization was found to be more in Fournier's gangrene (Mean 41 days).

\section{CONCLUSION}

The commonest cause for acute scrotum is epididymo-orchitis followed by torsion testis and Fournier's gangrene. Presence of scrotal swelling with pain is the most common feature followed by fever. Patients with Fournier's gangrene can present with septicaemic shock. The duration of symptoms is less in case of epididymo-orchitis than in case of Fournier's gangrene. Presence of urinary symptoms, similar complaints in the past is an important factor for acute scrotum. Involvement of right side is more common than left side. Routine investigations like urine analysis, haemogram and special investigations like USG are not always very much conclusive to the final diagnosis, but are supportive to clinical diagnosis. Since the scrotal disease may represent inherent disease of testis, epididymis and other intrascrotal structure which may affect the entire life of the patient in the form of sterility, so they need aggressive treatment.

\section{KEYWORDS}

Acute Scrotum, Epididymo-Orchitis, Torsion Testis.

HOW TO CITE THIS ARTICLE: Hazarika A, Kumar KS, Bora PP. Clinical study on acute scrotal swellings in Adichunchanagiri Hospital and Research Centre. J. Evolution Med. Dent. Sci. 2016;5(30):1522-1527, DOI: 10.14260/jemds/2016/359

\section{INTRODUCTION}

Acute scrotum is defined as, "the acute onset of pain and swelling of the scrotum that requires either emergency surgical intervention or specific medical therapy. ${ }^{1 "}$ Severe acute scrotal conditions can present in similar way, testicular torsion is by far the most significant. Testicular torsion is a real surgical emergency as testicular salvage reduces with passage of time. The other conditions that presents in similar way to testicular torsion include torsion of appendix testis, epididymo-orchitis, trauma to testis, haematocoele, etc.

Financial or Other, Competing Interest: None.

Submission 14-01-2016, Peer Review 19-02-2016,

Acceptance 25-02-2016, Published 12-04-2016.

Corresponding Author:

Dr. Abinash Hazarika,

Professor's Quarters, B. Block - 22,

AIMS, B. G. Nagara--571448,

Nagamangala Taluk,

Karnataka.

E-mail: hazarikadrabinash@gmail.com

DOI: 10.14260/jemds/2016/359
Disease primarily located elsewhere can present with signs and symptoms in the scrotum. Examples are haemoperitoneum and meconium peritonitis. Similarly, a torsion testis can present with abdominal pain, nausea and vomiting. This suggests that scrotum cannot be looked upon as an area isolated from the rest of the body.

In most of the patients, it should be possible to establish a reasonably accurate diagnosis based on detailed history and physical examination combined with the appropriate use of imaging studies.

A variety of investigations have been described in the management of acute scrotal conditions. These include an array of tests from a simple urine examination to more sophisticated forms like ultrasonography, Doppler studies and radionucleotide scanning.

Despite all the investigations, many of which are available only in few centers in India, early scrotal exploration remains to be one of the most important diagnostic as well a therapeutic modality. 


\section{OBJECTIVES OF THE STUDY}

- To ascertain various types of acute scrotal swellings admitted in general surgical wards of Adichunchanagiri Institute of Medical Sciences.

- To study the differential diagnosis for common causes of painful scrotum.

- To study pathology, clinical presentation and management of different acute scrotal conditions.

\section{MATERIALS AND METHODS}

\section{Source of Data}

The material for this study was obtained from patients admitted to general surgical wards of Adichunchanagiri Institute of Medical Sciences with acute scrotal swellings being included in the study from July 2013 to July 2015 and were evaluated clinically as well as with additional investigations.

\section{Methods of Collection of Data}

Clinical features, symptomatology, investigations, operative findings, postoperative complications, morbidity and mortality were entered and analysed. Patients were followed up for 1 month to 6 months period wherever necessary for any postop complications, etc. A total of 90 patients were studied.

\section{Inclusion Criteria}

All patients admitted in general surgical wards of Adichunchanagiri Institute of Medical Sciences with acute scrotal swellings were included in the study.

\section{Exclusion Criteria}

Patients with painless scrotal swellings and chronic scrotal pain will be excluded from the study.

\section{RESULTS AND DISCUSSION}

Study consists of analysis of 90 patients of acute scrotal swellings admitted in General Surgical wards of Adichunchanagiri Institute of Medical Sciences, B.G. Nagara from July 2013 - July 2015.

\section{Incidence of Various Types of Lesions}

The incidence of various conditions, which led to acute scrotum were found as follows.

\begin{tabular}{|c|c|c|c|}
\hline $\begin{array}{l}\text { Sl. } \\
\text { No. }\end{array}$ & Lesion & No. of Cases & Percentage \\
\hline 1. & Epididymo-orchitis & 39 & $43.33 \%$ \\
\hline 2. & Orchitis & 3 & $3.33 \%$ \\
\hline 3. & Epididymitis & 4 & $4.44 \%$ \\
\hline 4. & Fournier's gangrene & 15 & $16.67 \%$ \\
\hline 5. & Pyocele & 4 & $4.44 \%$ \\
\hline 6. & Haematocele & 2 & $2.22 \%$ \\
\hline 7. & Torsion testis & 19 & $21.11 \%$ \\
\hline 8. & Scrotal wall abscess & 2 & $2.22 \%$ \\
\hline \multirow[t]{2}{*}{9.} & Testicular abscess & 2 & $2.22 \%$ \\
\hline & TOTAL & 90 & $99.98 \%$ \\
\hline \multicolumn{4}{|c|}{ Table 1: Incidence of Lesions } \\
\hline
\end{tabular}

In our study, Acute epididymo-orchitis (43.33\%) is the commonest cause for acute scrotal pathology followed by testicular torsion (21.11\%) and Fournier's gangrene $(16.67 \%)$.

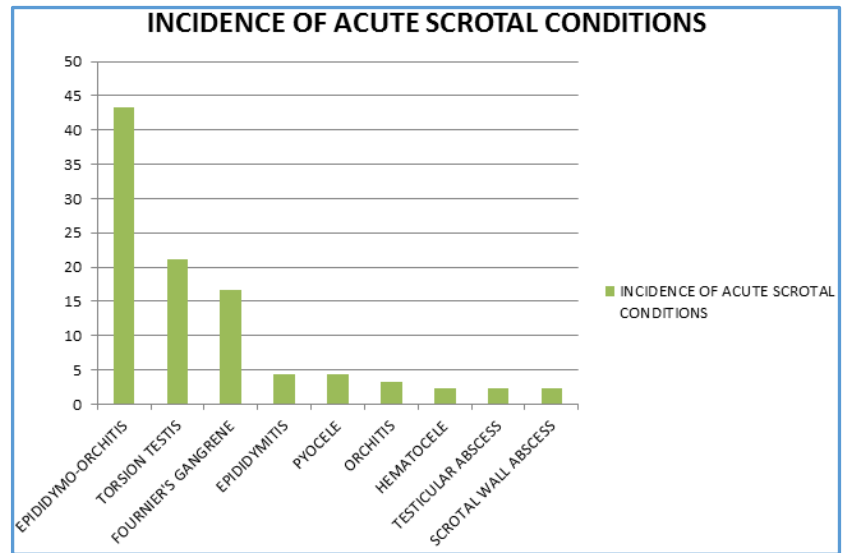

In large series reported by Cass et al., $72.57 \%$ had epididymitis compared to $20.67 \%$ cases of testicular torsion. ${ }^{2}$ But in study conducted by NH Moharib et al., testicular torsion $(33.92 \%)$ was the most common cause for acute scrotal pathology followed by torsion of hydatid of Morgagni. ${ }^{3}$ Epididymitis was found in $8.92 \%$ of cases.

In a study conducted by NA Watkin et al., torsion of testis was the commonest diagnosis of 39.5\%.4 Torsion of testicular appendage was $29 \%$ and epididymo-orchitis was $15 \%$, remaining $16 \%$ consisted of other scrotal condition.

\section{Incidence of Age}

\begin{tabular}{|c|c|c|}
\hline Age in Years & No. of Cases & Percentage \\
\hline $11-20$ & 16 & $17.78 \%$ \\
\hline $21-30$ & 20 & $22.22 \%$ \\
\hline $31-40$ & 14 & $15.56 \%$ \\
\hline $41-50$ & 15 & $16.67 \%$ \\
\hline $51-60$ & 12 & $13.33 \%$ \\
\hline $61-70$ & 12 & $13.33 \%$ \\
\hline $71-80$ & 1 & $1.11 \%$ \\
\hline TOTAL & $\mathbf{9 0}$ & $\mathbf{1 0 0 \%}$ \\
\hline \multicolumn{3}{|c|}{ Table 2: Incidence of Age } \\
\hline
\end{tabular}

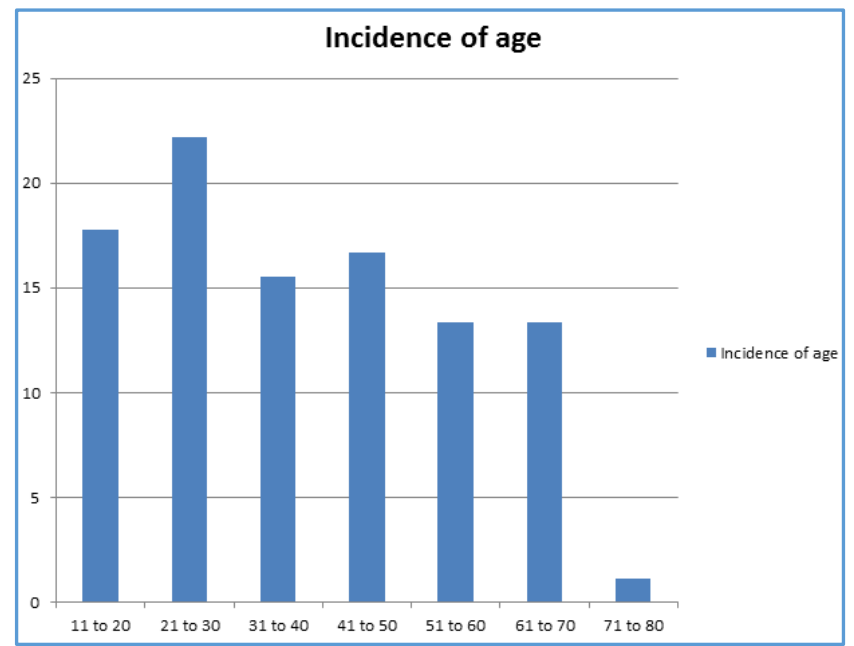

The overall age incidence is shown in the table. The maximum incidence occurred between the age group 21-30 years. In our study, the age incidence for acute epididymoorchitis was maximum in the $20-30$ group (30.77\%).

The mean age for the occurrence for epididymo-orchitis was 36.79 years, which differs from the study conducted by NA 
Watkin (21.3 years). ${ }^{4}$ The mean age for the occurrence for Fournier's gangrene was 53.53 years, which correlates with the study conducted by RB Jones et al. (51.3 years). ${ }^{5}$

\section{Duration of Symptoms}

\begin{tabular}{|c|c|c|}
\hline Duration & No. of Cases & Percentage \\
\hline $0-24$ hours & 2 & $2.22 \%$ \\
\hline $1-7$ days & 55 & $61.11 \%$ \\
\hline $8-15$ days & 31 & $34.44 \%$ \\
\hline $16-30$ days & 2 & $2.22 \%$ \\
\hline > 30 days & - & - \\
\hline TOTAL & $\mathbf{9 0}$ & $\mathbf{9 9 . 9 9 \%}$ \\
\hline \multicolumn{2}{|r}{ Table 3: Duration of Symptoms } \\
\hline
\end{tabular}

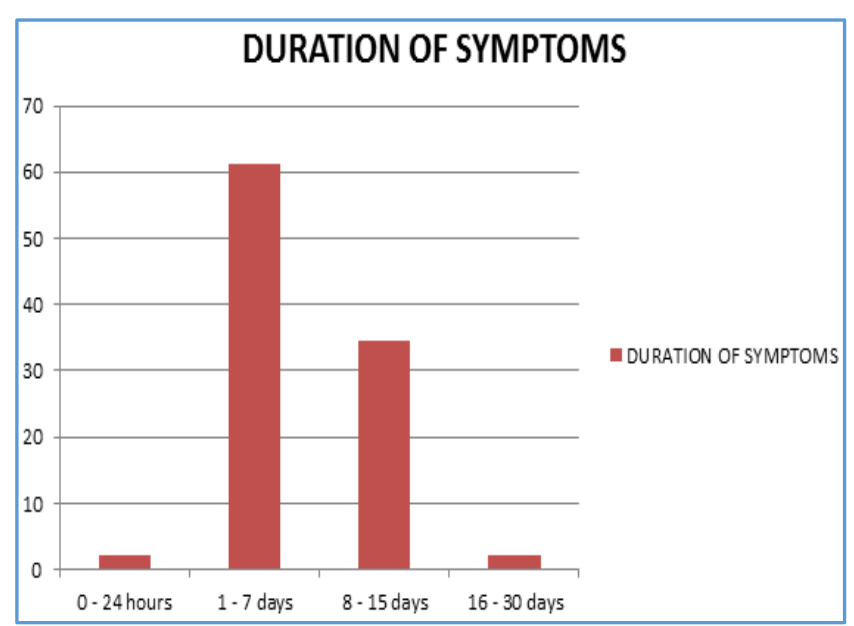

Duration of symptoms varied from few hours to as long as one month.

The shortest duration of symptoms in this study was 4 hours and longest duration was one month. In the study conducted by Thorsteinn et al., the shortest duration of symptoms was 3 hours and longest was 21 days. ${ }^{6}$

The average duration of pain from onset till presentation in case of epididymo-orchitis was 3.54 days, whereas it was 4 days in a study conducted by Ricardo et al. ${ }^{7}$

The average duration of symptoms from onset till presentation in case of Fournier's gangrene was 9.6 days in our study.

In our study shortest duration for presentation is 4 hours in case of two of testicular torsion, both cases underwent immediate scrotal exploration after appropriate investigation and were able to save testis in both cases, thus emphasizing the importance of time factor and early scrotal exploration in suspected cases of torsion testis.

\section{Predisposing Factors}

\begin{tabular}{|c|c|c|}
\hline History & No. of Cases & Percentage \\
\hline Trauma & 5 & $5.56 \%$ \\
\hline Urinary symptoms & 25 & $27.77 \%$ \\
\hline Similar complaints & 6 & $6.67 \%$ \\
\hline STD exposure & 2 & $2.22 \%$ \\
\hline Idiopathic & 52 & $57.77 \%$ \\
\hline TOTAL & $\mathbf{9 0}$ & $\mathbf{9 9 . 9 9 \%}$ \\
\hline \multicolumn{2}{|c|}{ Table 4: History of Predisposing Factors } \\
\hline
\end{tabular}

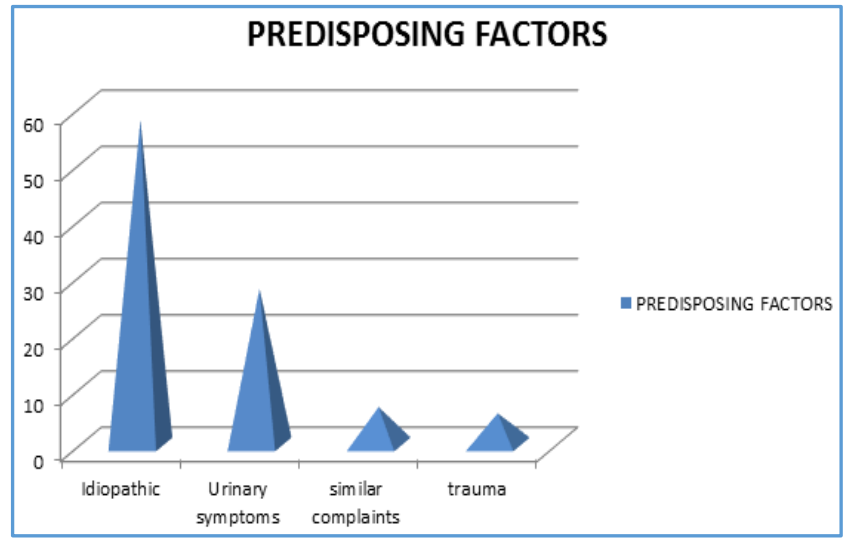

In our study there was history of trauma in two cases of haematocele, two cases of epididymo-orchitis and one case of testicular torsion.

There was history of urinary symptoms in 22 cases of epididymo-orchitis, 2 cases epididymitis and 1 case of pyocele. There was history of similar complaints in the past in 6 cases with epididymo-orchitis. There was exposure to STD in two cases of epididymo-orchitis.

Idiopathic were the most common, constituting about $57.77 \%$ of the total cases studied.

In study conducted by Ricardo C Del, Villar of 45 cases, history of similar complaints in the past was found in 2 cases of epididymitis and in 6 cases of torsion testis. Also there was history of trauma in 7 cases of epididymitis and in 3 cases of torsion testis. Dysuria was present in 7 cases of epididymitis and 1 case of torsion. ${ }^{7}$

\section{Presentation of Cases}

\begin{tabular}{|c|c|c|}
\hline Symptoms & No. of Cases & Percentage \\
\hline Swelling & 90 & $100 \%$ \\
\hline Pain & 90 & $100 \%$ \\
\hline Fever & 55 & $61.11 \%$ \\
\hline Burning micturition & 30 & $33.33 \%$ \\
\hline Difficulty passing urine & 3 & $3.33 \%$ \\
\hline Pain abdomen & 2 & $2.22 \%$ \\
\hline
\end{tabular}

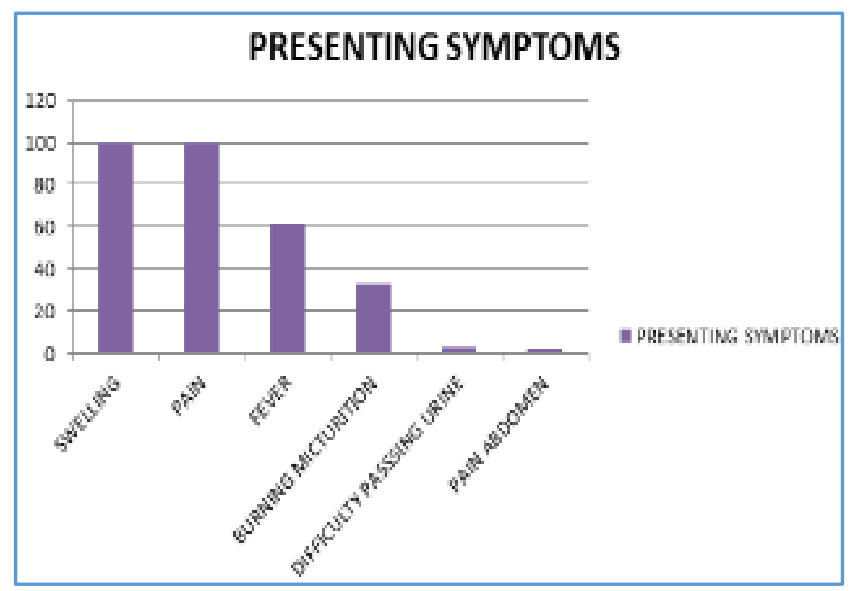

All cases had swelling of scrotum associated with pain at the time of presentation. 
$61.11 \%$ patients had history of fever, while $33.33 \%$ patients had history of burning micturition.

There was difficulty passing urine in 3 patients and pain abdomen with scrotal pain in 2 cases.

Fever was present in $30.77 \%$ cases of epididymo-orchitis cases and $80 \%$ cases of Fournier's gangrene. Burning micturition was found in $46.15 \%$ cases of epididymo-orchitis.

\section{Distribution of Symptoms}

\begin{tabular}{|c|c|c|}
\hline Side & No. of Cases & Percentage \\
\hline Right & 42 & $46.67 \%$ \\
\hline Left & 31 & $34.44 \%$ \\
\hline Bilateral & 17 & $18.89 \%$ \\
\hline Total & $\mathbf{9 0}$ & $\mathbf{1 0 0} \%$ \\
\hline \multicolumn{3}{|c|}{ Table 6: Distribution of Symptoms } \\
\hline
\end{tabular}

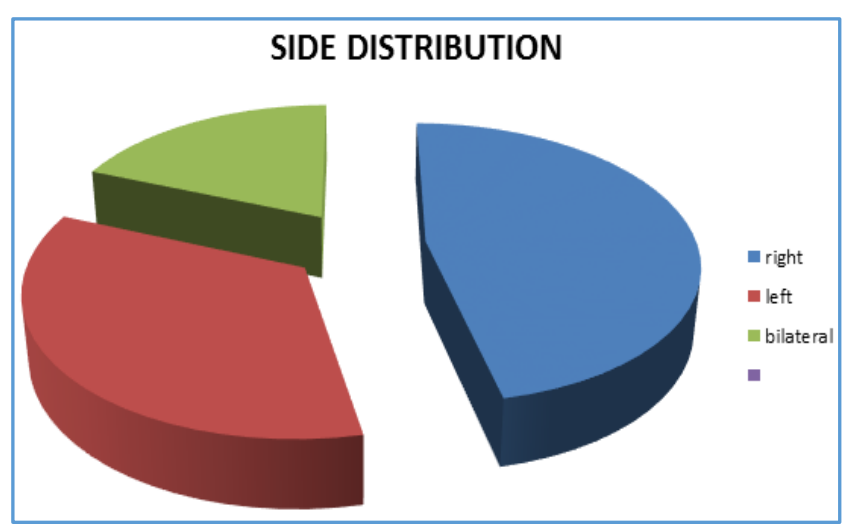

In this study of 90 cases, it was observed that acute scrotal swelling was common on right side occurring for $46.67 \%$ cases as compared to left side (34.44\%). Bilateral swellings were found in $18.89 \%$ of cases.

\section{Investigations}

For all 90 cases, routine investigations like haemogram and urine analysis were done. Special investigations like USG of scrotum and colour Doppler were also done.

The urine examination showed significant pus cells in 39 (43.33\%) cases.

There was increase in total leucocyte count in 54 (60\%) cases showing acute infection. Thorstein Gislason showed that leucocytosis was present in $44 \%$ cases, whereas in our study it was $60 \%{ }^{6}$

On ultrasonography in case of acute epididymo-orchitis, testis was diffusely hypoechoic and swollen. The epididymis was hypoechoic and swollen with colour Doppler showing increased vascularity of both epididymis and testis.

In case of testicular abscess, there was hypoechoic shadow in the test showing collection of fluid. In case of pyocele, echogenicity around the testis was not uniform showing uniform purulent collection with thickened scrotal sac. A similar picture was found in haematocele. Hence, it is difficult to differentiate haematocele from pyocele ultrasonologically.

In case of scrotal wall oedema, USG revealed a thickened scrotal wall. Colour Doppler plays a vital role in diagnosis of testicular torsion and differentiating it from other acute scrotal conditions.
In our study of 19 cases of testicular torsion, all cases were diagnosed by colour Doppler. Also in 2 cases of testicular torsion due to early reporting (In 4 hours) and early diagnosis with colour Doppler they were explored early resulting in testicular salvage.

But colour Doppler may not be available in all centers and in such conditions immediate exploration is the ideal choice to save testis when history and clinical examination suggest possibility of torsion.

\section{Treatment}

\begin{tabular}{|c|c|c|c|}
\hline $\begin{array}{l}\text { Sl. } \\
\text { No. }\end{array}$ & Treatment Given & Cases & $\%$ \\
\hline \multirow[t]{2}{*}{1} & Conservative & 46 & $51.11 \%$ \\
\hline & Surgical & & \\
\hline 2 & Orchidectomy & 18 & $20 \%$ \\
\hline 3 & Orchidopexy & 1 & $1.11 \%$ \\
\hline 4 & $\begin{array}{l}\text { Debridement+/- secondary } \\
\text { suturing/skin grafting }\end{array}$ & 15 & $16.67 \%$ \\
\hline 5 & Incision and drainage & 2 & $2.22 \%$ \\
\hline 6 & $\begin{array}{c}\text { Scrotal exploration+pyocele } \\
\text { evacuation }\end{array}$ & 4 & $4.44 \%$ \\
\hline 7 & $\begin{array}{l}\text { Scrotal exploration+haematocele } \\
\text { evacuation }\end{array}$ & 2 & $2.22 \%$ \\
\hline 8 & $\begin{array}{c}\text { Scrotal exploration+testicular } \\
\text { abscess drainage }\end{array}$ & 2 & $2.22 \%$ \\
\hline \multicolumn{4}{|c|}{ Table 7: Treatment } \\
\hline
\end{tabular}

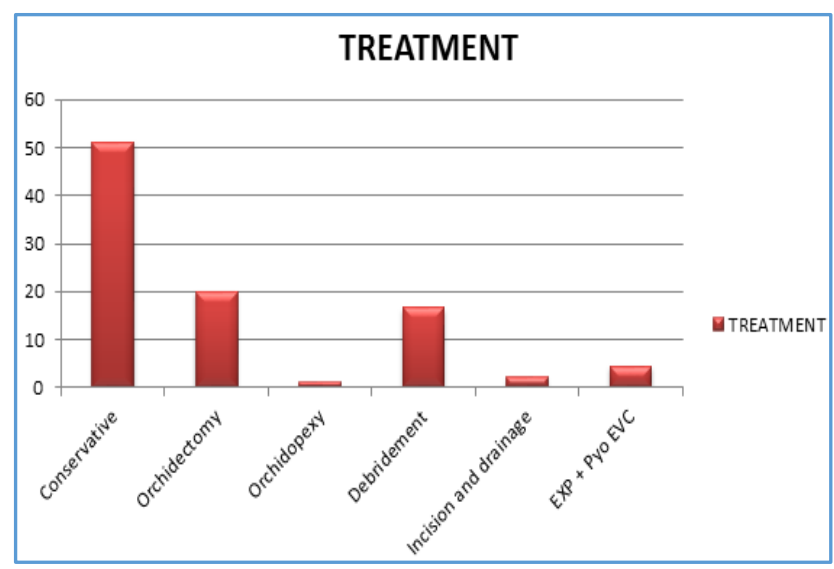

\section{Conservative Treatment}

In this series of 90 cases, 46 cases (51.11\%) were managed conservatively; 39 cases of epididymo-orchitis, 1 case of orchitis, 4 cases of epididymitis, 3 cases of orchitis were treated conservatively with rest, scrotal supports, antibiotics and analgesics. Conservative treatment was given for 7 to 21 days.

\section{Surgical Treatment}

Incision and drainage of scrotal wall abscess was carried out for two cases. Scrotal exploration with drainage of testicular abscess was done in two cases.

Out of 15 cases of Fournier's gangrene only debridement was carried out in 4 patients. Multiple debridement followed by secondary suturing in 5 cases and skin grafting in 6 cases was carried out.

Scrotal exploration with evacuation of haematoma and repair of ruptured testis was carried out in 2 patients. Orchidectomy was required in 18 cases of testicular torsion on 
affected side; 2 cases of torsion testis were found viable and hence proceeded with orchidopexy on affected side.

\section{Results of Treatment}

Patients treated conservatively responded well with complete recovery. In surgically treated patients, postoperative recovery was uneventful with 3 cases developing wound infection as a complication.

The average hospital stay in patients with conservative treatment was 7.27 days. Patients with Fournier's gangrene the average hospital stay was 41.29 days. In other cases treated surgically, the average hospital stay was 11.42 days.

\section{Followup}

All patients were followed up for a period of 1 month to 6 months. None of the patients had complications.

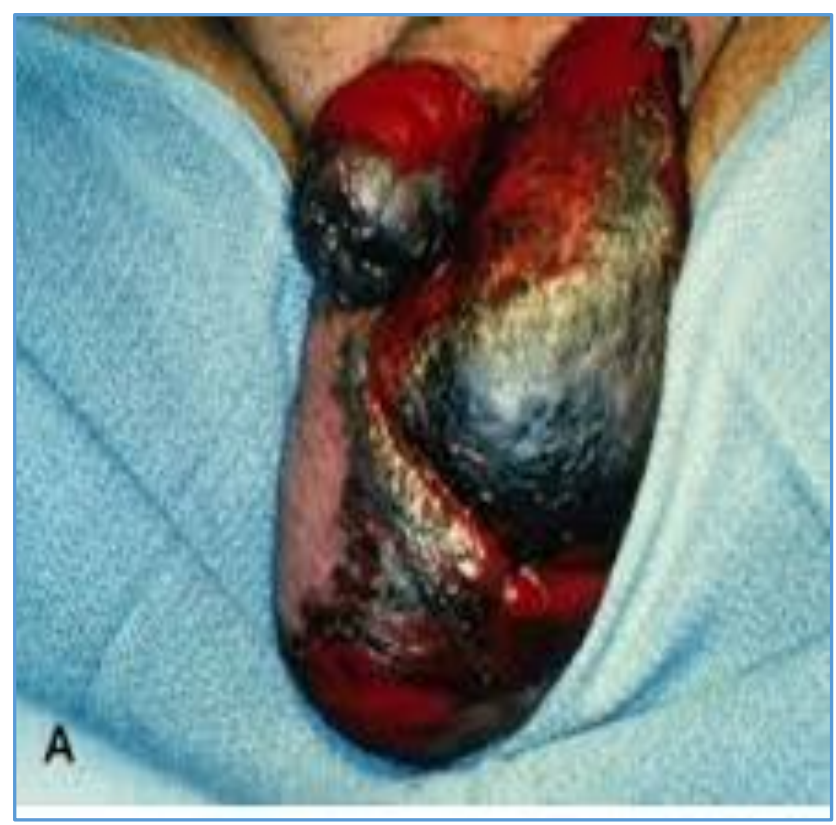

Fig. 1: Fournier Gangrene

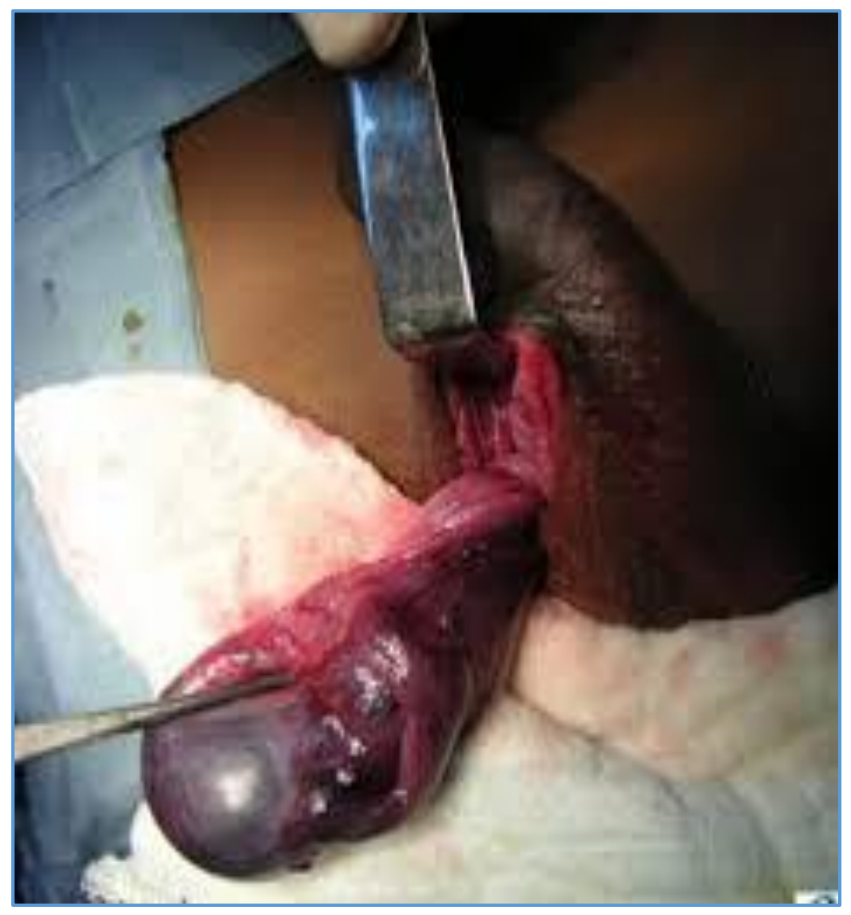

Fig. 2: Torsion Testis

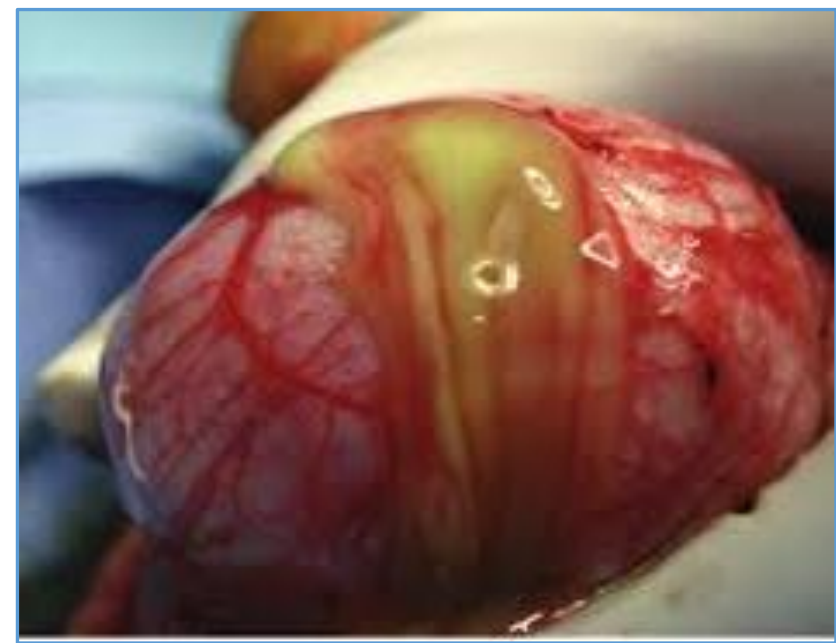

Fig. 3: Testicular Abscess

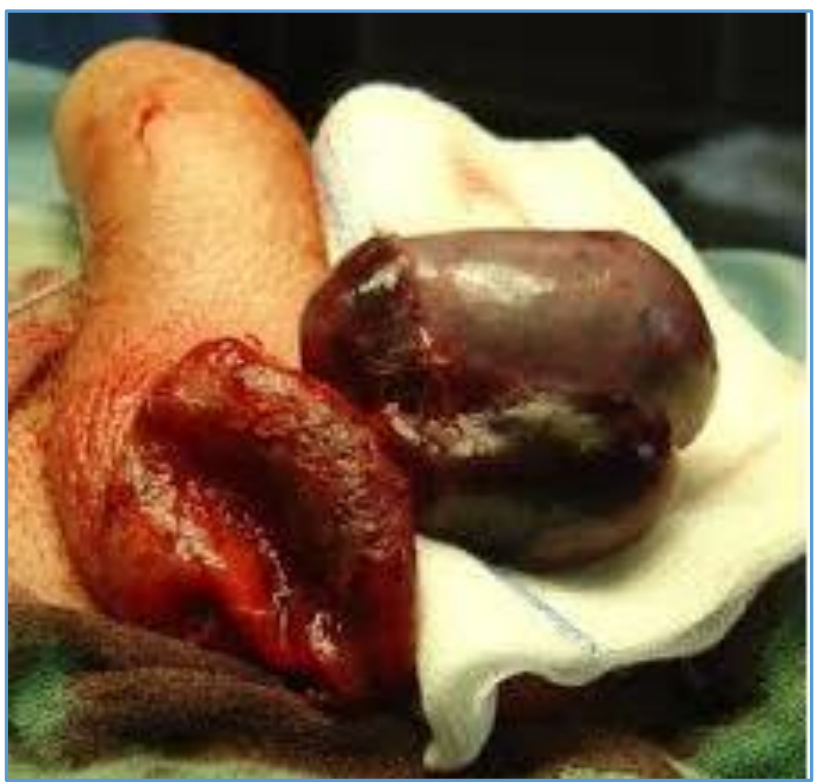

Fig. 4: Haematocele

\section{SUMMARY}

A case study of 90 cases of acute scrotal swellings admitted in general surgical wards and casualty of Adichunchanagiri Institute of Medical Sciences, B.G. Nagara, from July 2013 - July 2015 was carried out.

In present study, clinical analysis of 90 cases of acute scrotal swelling is presented.

The evaluation of the patient is done. Treatment of each case has been described in detail.

Acute scrotal swellings appeared to be a common condition affecting the male. Among acute scrotal swellings, epididymo-orchitis was found to be the commonest followed by testicular torsion and Fournier's gangrene.

Acute scrotal swellings were common in younger individuals. The maximum incidence occurred during $3^{\text {rd }}$ decade. The mean age for occurrence for epididymo-orchitis was 36.79 years and 55.53 years for Fournier's gangrene.

The factors like trauma and urinary symptoms had definite effect on the disease. History of similar complaints in the past was common in cases of epididymo-orchitis.

In $55.77 \%$ of the cases, the cause was not evident (i.e. idiopathic). 
The duration of symptoms varied from few hours to as long as a month.

The shortest duration of symptoms in this series was 4 hours.

The average duration of pain from onset till presentation in case of epididymo-orchitis was 3.54 days and in case of Fournier's gangrene was 9.6 days.

In our study shortest duration for presentation is 4 hours in case of two of testicular torsion, both cases underwent immediate scrotal exploration after appropriate investigation and were able to save testis in both cases. Thus emphasizing the importance of time factor and early scrotal exploration in suspected cases of torsion testis.

Scrotal swelling associated with pain was the common presenting feature, fever and burning micturition being the next common symptoms.

Presentation with features of septicaemic shock was also noted in case of Fournier's gangrene.

Unilateral involvement of scrotum on right side was common, accounting for $46.67 \%$ of the cases. Bilateral involvement was seen in almost 15 cases of Fournier's gangrene.

Haemogram, urine analysis were not conclusive, but were supportive to clinical diagnosis. USG combined with colour Doppler has high accuracy in detecting testicular torsion.

Conservative treatment was given in the form of rest, scrotal support, antibiotics and analgesics for 7 days to 3 weeks. All cases treated conservatively responded very well. Patients treated surgically also responded well.

The period of hospitalization was found to be more in Fournier's gangrene (Mean 41 days). All patients were followed up for a period of one month to six months. None of the patients had complications.

\section{CONCLUSION}

Acute scrotal swellings are common in younger individuals with variable symptomatology. Such conditions presenting to emergency department needs careful examination, proper evaluation and prompt treatment.

The commonest cause for acute scrotum is epididymoorchitis followed by torsion testis and Fournier's gangrene.

Presence of scrotal swelling with pain is the most common feature followed by fever. Patients with Fournier's gangrene can present with septicaemic shock.

The duration of symptoms is less in case of epididymoorchitis than in case of Fournier's gangrene.

Presence of urinary symptoms, similar complaints in the past is an important factor for acute scrotum. Involvement of right side is more common than left side.
Routine investigation like urine analysis, haemogram and special investigations like USG are not always very much conclusive to the final diagnosis but are supportive to clinical diagnosis. Since the scrotal disease may represent inherent disease of testis, epididymis and other intrascrotal structure which may affect the entire life of the patient in the form of sterility, so they need aggressive treatment.

Conservative treatment with rest, scrotal support, antibiotics and analgesics is more effective in case of epididymo-orchitis and epididymitis.

Emergency surgical exploration proved to be the best in case of Fournier's gangrene and pyocele. It does not involve major expenditure with negligible surgical morbidity and also proved to be the best investigation modality as definite diagnosis can be reached in every case with exploration.

Followup of acute scrotal cases is very essential to find out the complications in the form of sterility, development of fistulas and involvement of the contralateral side at a later period, so as to take the total care of the patient with acute scrotal conditions.

In our study shortest duration for presentation is 4 hours in case of two of testicular torsions, both cases underwent immediate scrotal exploration after appropriate investigation and were able to save testis in both cases. Thus emphasizing the importance of time factor and early scrotal exploration in suspected cases of torsion of testis.

Rare acute conditions like scrotal fat necrosis, HS purpura, testicular tumour, etc. have not been encountered in the present study. So, no remarks can be made in this respect.

\section{REFERENCES}

1. Willam CS. Acute scrotal pathology. Surg $\mathrm{Cl} \mathrm{N}$ America 1982;62(6):955-70.

2. Cass AS, Cass BP, Veeraraghavan K. Immediate exploration of the unilateral acute scrotum in young male subjects. J Urol 1980;124(6):829-32.

3. Moharib NH, Krahn HP. Acute scrotum in children with emphasis on torsion of spermatic cord. J Urol 1970;104(4):601-03.

4. Watkin NA, Reiger NA, Moisey CU. Is in the conservative management of the acute scrotum justified on clinicalgrounds? J Urol 1996;78(4):623-7.

5. Jones RB, Hirschmann JV, Brown GS, et al. Fournier's syndrome: necrotising subcutaneous infection of the male genitalia. J Urol 1979;122(3):279-82.

6. Thorstienn Gislason, Rekynold FN, Gregory JG. Acute epididymitis in boys: a 5-year study. J Urol 1980;124(4):533-34

7. James H Barada, Weingartan JL, Chromie WJ. Testicular salvage and age-related delay in presentation of testicular torsion. J Urol 1989;142(3):746-48. 